\title{
Startup of RAPID-L Lunar Base Reactor by Lithium Release Module*
}

\author{
Mitsuru KAMBE** \\ ** Central Research Institute of Electric Power Industry (CRIEPI) \\ 2-11-1, Iwado-kita, Komae-shi, Tokyo, 201-8511 JAPAN \\ E-mail:kambe@criepi.denken.or.jp
}

\begin{abstract}
The $200 \mathrm{kWe}$ uranium-nitride fueled lithium cooled fast reactor concept RAPID-L to be combined with thermoelectric power conversion system for lunar base power system is demonstrated. Unique challenges in reactivity control systems design have been attempted in RAPID-L concept. The reactor involves the following innovative reactivity control systems: Lithium Expansion Modules (LEM) for inherent reactivity feedback, Lithium Injection Modules (LIM) for inherent ultimate shutdown, and Lithium Release Modules (LRM) for automated reactor startup. All these systems adopt lithium- 6 as a liquid poison instead of conventional $\mathrm{B}_{4} \mathrm{C}$ rods or Be reflectors. These systems are effective independent of the magnitude and direction of the gravity force. In 2006, however, the following design amendment has been made. 1) $\mathrm{B}_{4} \mathrm{C}$ poison rods were added to ensure criticality safety in unintended positive reactivity insertion by LRMs due to fire in the launch phase accident; because LRM freeze seal melts at $800^{\circ} \mathrm{C}$ which result in positive reactivity insertion. 2) Lower hot standby temperature of $200^{\circ} \mathrm{C}$ was adopted instead of conventional $800^{\circ} \mathrm{C}$ to reduce the external power at the startup. In this paper, development of the LRM orifice which dominates the startup transient of RAPID-L is discussed. An attention was focused how to achieve sufficiently small flow rate of ${ }^{6} \mathrm{Li}$ in the orifice because it enables moderate positive reactivity insertion rate. The LRM orifice performance has been confirmed using $0.5 \mathrm{~mm}$ diameter SUS316 orifice/lithium flow test setup in the glove box.
\end{abstract}

Key words: Fast Reactor, Micro Nuclear Reactor, Reactor Startup, Lunar Base

\section{Introduction}

In previous fast reactors, all the reactor operations including startup, shutdown and power control should be achieved by control rods made of $\mathrm{B}_{4} \mathrm{C}$ absorber and/or $\mathrm{Be}$ reflectors. Such control systems involve a number of specific issues; reliability of actuation and drive mechanisms, scram capability under seismic condition, and unprotected transient overpower (UTOP) mitigation potential. Furthermore, future fast reactor plants will have greater safety requirements and operational demands. Despite several approaches ${ }^{1-3}$ to enhance inherent safety by self-actuated shutdown capability, no attempts except the inherent secondary shutdown system ${ }^{4}$ (ISSS) and the gas expansion module ${ }^{5}$ (GEM) have been made to apply measures without absorber rods. Both the ISSS and GEM are, by their own nature, effective for unprotected loss of flow (ULOF) but not for transients such as UTOP. Another issue to be considered in future fast reactors, especially in space reactors, is the simplicity of operation. So far, skillful operators are essential for reactor startup in 
conventional plants. Fully automated reactor startup has never been reported except for spacecraft nuclear reactors ${ }^{6}$.

This study concentrated on the establishment of operator-free fast reactor concept RAPID-L ${ }^{7}$, designed for lunar base activities. RAPID-L is one of the variants of fast reactor concept RAPID ${ }^{8}$ (Refueling by All Pins Integrated Design), which enable quick and simplified refueling 2 months after reactor shutdown. A significant advantage of RAPID-L is the introduction of the innovative reactivity control systems: lithium expansion module ${ }^{7,9}$ (LEM), lithium injection module ${ }^{7,9,10}$ (LIM) and lithium release module ${ }^{7,9}$ (LRM). LEM is the most promising candidate for improving inherent reactivity feedback. LEMs could realize burnup compensation and partial load operation. LIMs assure sufficient negative reactivity feedback in unprotected transients. LRMs enable an automated reactor startup by detecting the hot standby temperature of the primary coolant. All these systems utilize liquid poison of ${ }^{6} \mathrm{Li}$ and are actuated by highly reliable physical property (i.e. volume expansion of ${ }^{6} \mathrm{Li}$ for LEM, and freeze seal meltdown for LIM and LRM).

In the 2006 design phase ${ }^{11}$, an attention has been focused on the criticality safety at launch phase accident, especially on the fire which results in unintended positive reactivity insertion by LRMs because LRM freeze seal melts at $800^{\circ} \mathrm{C}$. In view of this, $\mathrm{B}_{4} \mathrm{C}$ poison rods as well as LRM were introduced. A definite advantage of LRM over $\mathrm{B}_{4} \mathrm{C}$ rod is that the former has no moving parts and requests no instrumentation, while the $\mathrm{B}_{4} \mathrm{C}$ rod ensures criticality safety in all accidental situations. Therefore both LRM and $\mathrm{B}_{4} \mathrm{C}$ rod is required.

Another issue in conventional RAPID-L design is the external power required at the startup. Approximately $3420 \mathrm{kWh}$ external power is required to heat up the reactor from cold equilibrium temperature $\left(-100^{\circ} \mathrm{C}\right)$ to the hot standby temperature $\left(800^{\circ} \mathrm{C}\right)$. To reduce such external power and to ensure criticality safety in any phase of the mission, poison rods are introduced in addition to above mentioned innovative control systems.

In this paper, development of the LRM orifice which dominates the startup transient of RAPID-L is discussed. The most important issue is how to achieve sufficiently small flow rate of ${ }^{6} \mathrm{Li}$ in the orifice because it enables moderate positive reactivity insertion rate. The LRM orifice performance has been confirmed using $0.5 \mathrm{~mm}$ diameter SUS316 orifice/lithium flow test setup in the glove box.

\section{Plant Concept}

\subsection{Overall Plant Design}

The conceptual design of RAPID-L consists of a $5000 \mathrm{kWt}-200 \mathrm{kWe}$ uranium-nitride fueled, lithium cooled, fast spectrum reactor with lithium inlet and outlet temperature of 1030 and $1100^{\circ} \mathrm{C}$, respectively. The reactor structure and the fuel cartridge are shown in Fig. 1. The reactor is basically a loop type configuration and a reactor vessel of $2 \mathrm{~m}$ in diameter and $6.5 \mathrm{~m}$ deep. The difference from conventional pool type reactor is the integrated fuel assembly. The core consists of approximately 2700 fuel elements. These entire elements are combined together by a core support grid and several spacer grids, and are assembled into a fuel cartridge as shown in Fig. 2. In this particular reactor concept, the reactor has neither diagrid nor core support structure because they are also integrated in a fuel cartridge.

From a general design standpoint, the integrity of the core support structure is of outstanding importance. Thus the most important in-service inspection (ISI) requirement is validation of the core support structure as this is entirely immersed in the coolant and therefore presents a difficult and currently unresolved problem. The RAPID concept makes it easier by adopting a combination of replaceable diagrid/core support structure and a permanent reactor vessel. Advantage has been taken of simple reactor vessel instead of conventional one with diagrid and core support structure; the simple reactor vessel would 
make ISI easier than it would be with more complex diagrid and core support structure. ISI of the reactor vessel can be conducted in each refueling. In this concept, the design lifetime of the replaceable core support grid as well as the fuel cartridge can be reduced to 10 years, those located in the relatively high flux regions (i.e., $10^{22} \mathrm{n} \mathrm{cm}^{-2}$ in 10 years). On the other hand, the reactor vessel can be designed as a permanent structure exposed to decreased neutron flux. To keep the final fluence of the reactor vessel under the design limit (i.e., $10^{21} \mathrm{n} \mathrm{cm}^{-2}$ in 20 years), neutron shielding materials must be effectively provided in the lower section of the fuel cartridge.

Electromagnetic

pumps and the fuel cartridge are connected by the connecting tubes. The reactor subsystem is

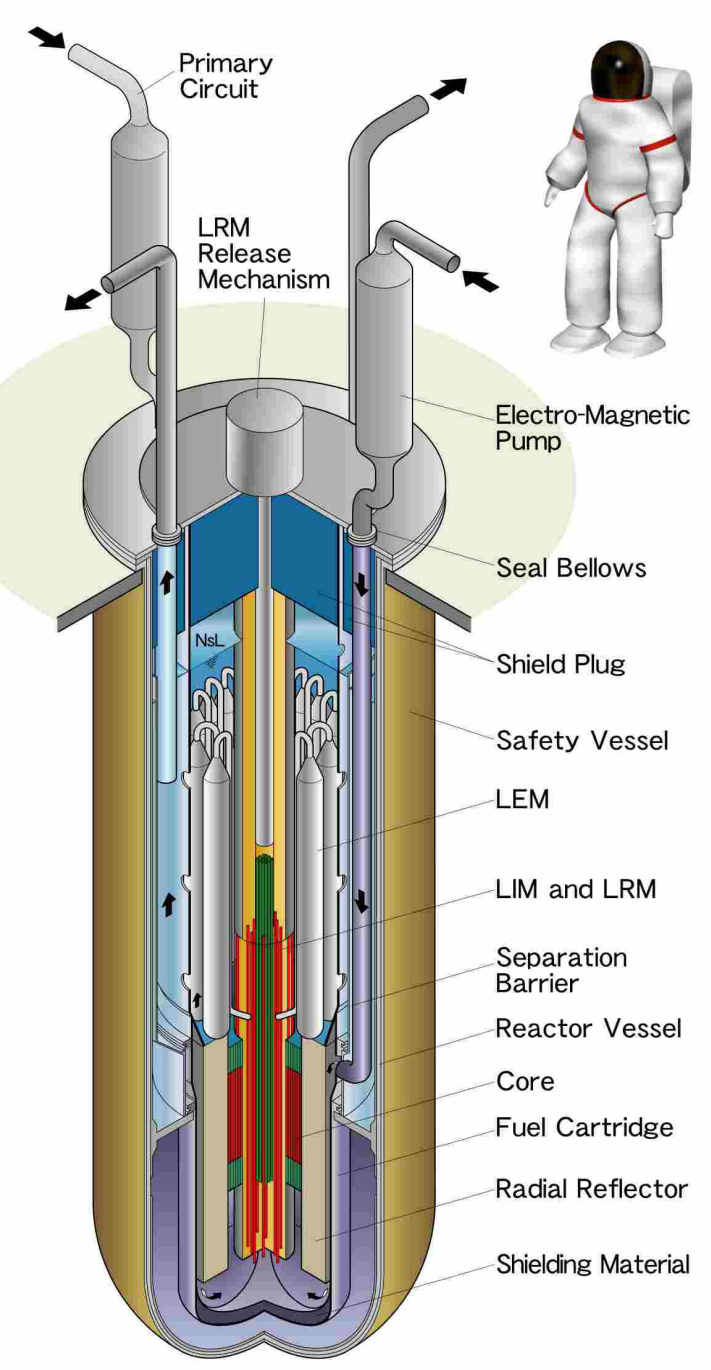

Fig.1 Reactor structure of RAPID-L

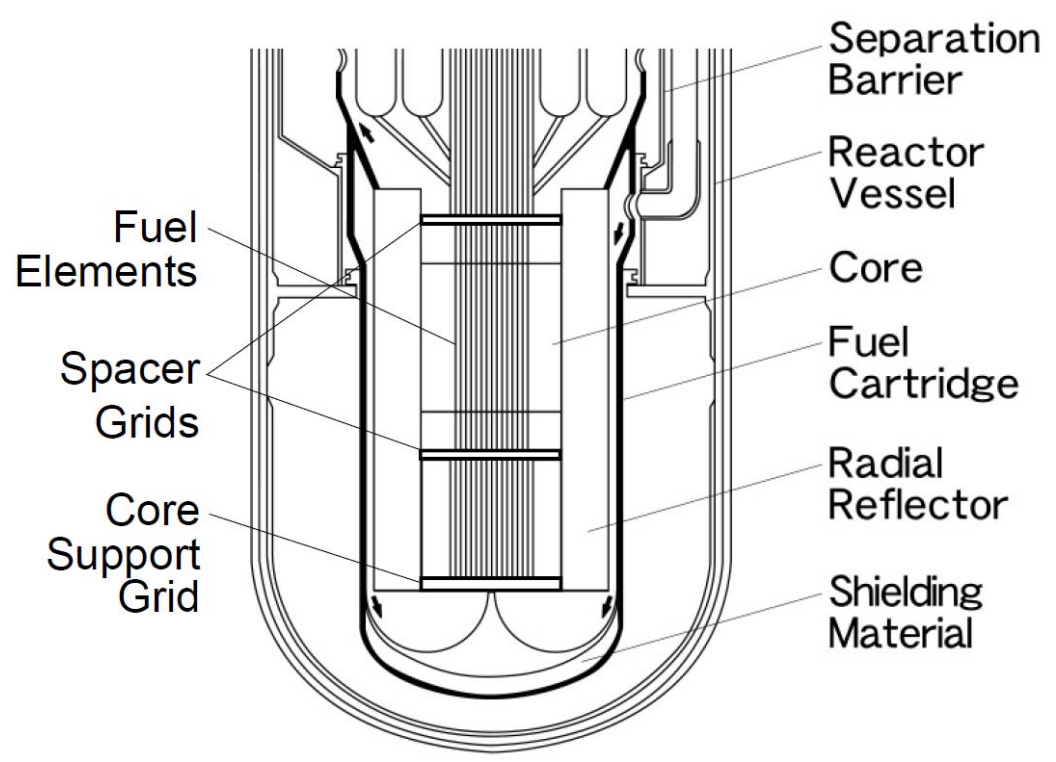

Fig. 2 Fuel cartridge detail 
characterized by RAPID refueling concept to eliminate conventional fuel handling systems. A substantial reactor block mass savings of less than a half over comparable liquid metal cooled fast reactor systems can be estimated. Its compact design makes it possible to assemble a whole structure in the workshop prior to the launch.

The overall nuclear power system is illustrated in Fig. 3. The reactor is located in an excavated cylindrical hole which provides shielding of gamma and neutron radiation.

The power conversion system consists of 4 power conversion segments placed around the reactor. Each segment has a pumped lithium heat rejection loop connected to cesium heat pipe radiators. The eight radiator panels are arranged in a vertical configuration extended radially from the power conversion segments. A thermal apron is placed between the radiator panels to reduce the lunar surface temperature and thus, reduce required radiator area. Each segment comprises 18 thermoelectric (TE) modules. Each TE module consists of 720 TE units with 12 sodium heat pipes on the hot sides and 13 cesium heat pipes on the cold sides. The secondary lithium inlet temperature of $800 \mathrm{~K}$ with the temperature rise of $46 \mathrm{~K}$ was determined to realize the optimum trade-off between the energy conversion system and the waste heat radiator system to minimize the total mass of the power system. Based on the TE cell efficiency of current state of the art, net efficiency of the system is estimated to be $4 \%$.

A performance breakdown of the nuclear power system is shown in Table 1.

The total mass of the system, including power conditioning is 15.8 metric tones. The system was designed to be launched by conventional launch vehicle (i.e. payload geometric envelope: $3.7 \mathrm{~m}$ diameter and $10 \mathrm{~m}$ long, payload maximum weight: $10 \mathrm{t}$ ). Two launches are sufficient to bring the whole system.

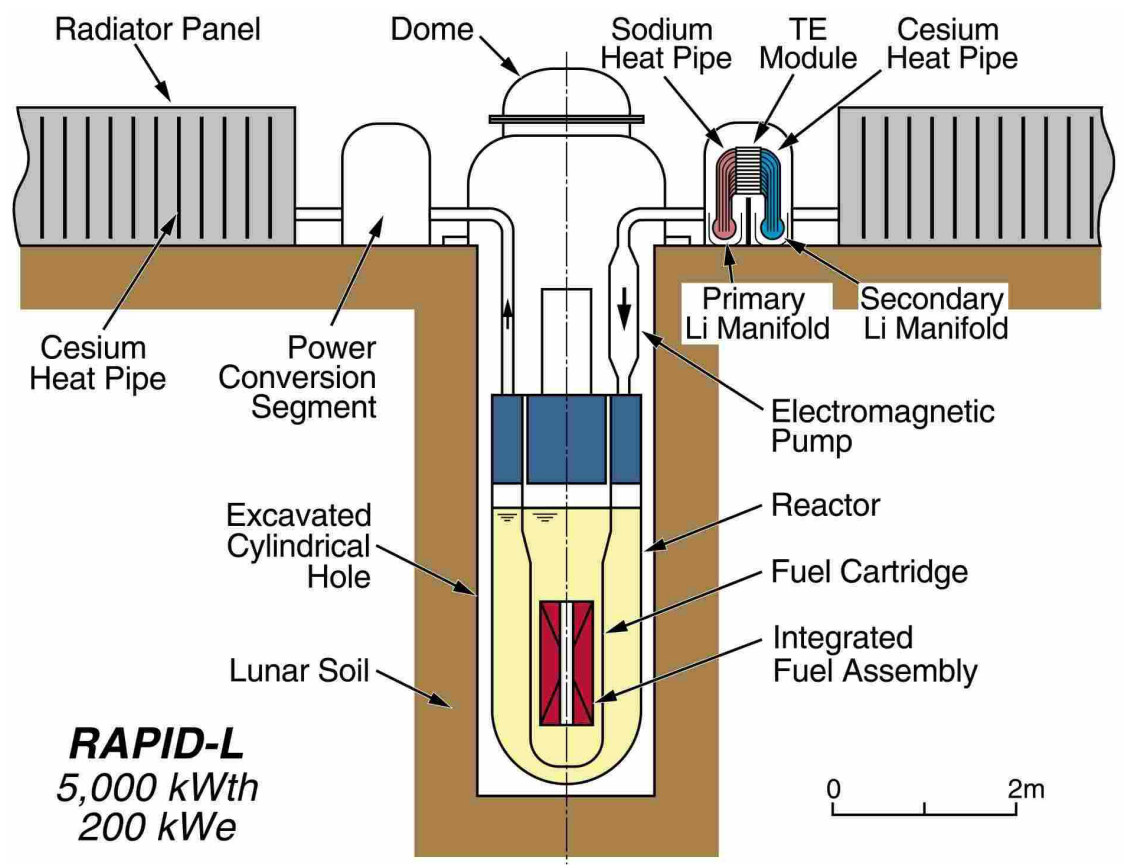

Fig.3 Nuclear power system layout

\subsection{Reactor Core Design}

The reactor core is a homogeneous design with two regions. The active core region is $600 \mathrm{~mm}$ diameter and $600 \mathrm{~mm}$ high with a center channel $120 \mathrm{~mm}$ diameter. The fuel chosen for the inner and outer core consists of $40 \%$ and $50 \%$ enriched uranium-nitride. The uranium enrichments were adjusted to minimize both the burnup reactivity swing and the 
radial peaking factor. The core performance parameters are shown in Table 2. The core Reynolds number is defined by the equivalent hydraulic diameter and the flow velocity in the pin bundle.

Table 1 Nuclear Power System Performance Parameters

\begin{tabular}{|ll|}
\hline & 5000 \\
Reactor thermal power $(\mathrm{kW}$ th) & 240 \\
Gross electrical output $(\mathrm{kWe})$ & 200 \\
Net electrical output $(\mathrm{kWe})$ & 20 \\
Plant design lifetime (years) & \\
& \\
Thermoelectric system & $1065 / 550$ \\
inlet/outlet temperature $\left({ }^{\circ} \mathrm{C}\right)$ & 5 \\
Conversion efficiency $(\%)$ & 4760 \\
& $573 / 527$ \\
Waste heat to reject $(\mathrm{kWth})$ & 240 \\
Radiator inlet $/ \mathrm{outlet} \mathrm{temperature}^{\circ}\left({ }^{\circ} \mathrm{C}\right)$ & \\
Radiator area $\left(\mathrm{m}^{2}\right)$ & \\
\hline
\end{tabular}

Table 2 Core Performance Parameters

\begin{tabular}{|ll|}
\hline Thermal nominal output $(\mathrm{kW})$ & 5000 \\
Active core height $(\mathrm{m})$ & 0.6 \\
Active core diameter $(\mathrm{m})$ & 0.6 \\
Core volume fraction & \\
(fuel/coolant/structure) & $52 / 32 / 16$ \\
${ }^{235} \mathrm{U}$ enrichment $(\%)$ & \\
(inner core/outer core) & $40 / 50$ \\
Design lifetime $($ year) & 10 \\
Burnup reactivity swing $(\$ / 10$ year) & 3.2 \\
Fuel pin outer diameter $(\mathrm{mm})$ & 8.0 \\
Fuel pin pitch (mm) & 9.04 \\
Number of fuel pins & 2700 \\
Peak linear power at BOL $(\mathrm{W} / \mathrm{cm})$ & 52 \\
Primary coolant & ${ }^{7} \mathrm{Li}(99.99 \%)$ \\
Primary coolant flowrate $(\mathrm{kg} / \mathrm{s})$ & 17.25 \\
Core inlet/outlet temperature $\left({ }^{\circ} \mathrm{C}\right)$ & $1030 / 1100$ \\
Average coolant velocity in the core $(\mathrm{m} / \mathrm{s})$ & 0.72 \\
Core Reynolds number & 5870 \\
Gas plenum height $(\mathrm{m})$ & 0.5 \\
Internal pressure of the fuel cladding at EOL core $(\mathrm{MPa})$ & 4 \\
\hline
\end{tabular}

\section{Reactivity Control Systems}

In addition to the conventional $\mathrm{B}_{4} \mathrm{C}$ poison rods, the reactor involves the following innovative reactivity control systems: Lithium Expansion Modules (LEM) for inherent reactivity feedback, Lithium Injection Modules (LIM) for inherent ultimate shutdown, and Lithium Release Modules (LRM) for automated reactor startup. All these systems adopt lithium- 6 as a liquid poison. These systems are effective independent of the magnitude and direction of the gravity force. 


\subsection{Lithium Expansion Module (LEM)}

The LEM is the most promising candidate for improving inherent reactivity feedback. The concept of LEM is illustrated in Fig. 4.

LEM is composed of an envelope of refractory metal in which liquid poison of $95 \%$ enriched ${ }^{6} \mathrm{Li}$ is enclosed. Lithium-6 is suspended in the upper part of the envelope by surface tension exerted on the gas-liquid interface. The

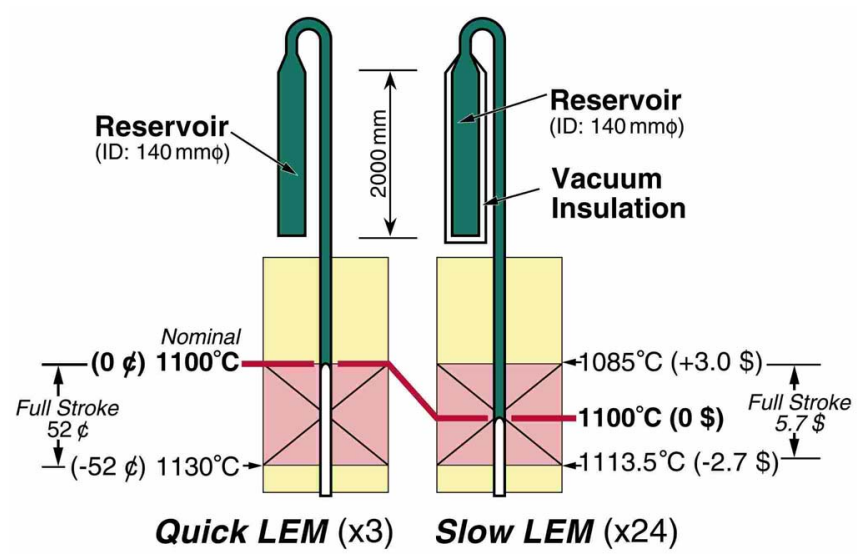

Fig.4 Elevation of the LEM gas-liquid interface LEM is actuated by the volume expansion of ${ }^{6} \mathrm{Li}$ itself. If the core exit temperature increases, the gas-liquid interface goes down and negative reactivity insertion can be achieved. LEM is effective independent of the magnitude and direction of the gravity force.

RAPID-L is equipped with 4 quick LEMs and 24 slow LEMs. Figure 3 indicates the locations of the gas-liquid interface of both LEMs and corresponding core outlet temperatures. In the figure, quasi-steady-state temperature variation is supposed.

\subsection{Lithium Injection Module (LIM)}

The LIM is another innovative device installed in RAPID-L to assure inherent safety. The concept of LIM is illustrated in Fig.5. LIM is also composed of an envelope in which $95 \%$ enriched ${ }^{6} \mathrm{Li}$ is enclosed. In case that the core outlet temperature exceeds the melting point of the freeze seal, ${ }^{6} \mathrm{Li}$ is injected by pneumatic mechanism from upper to lower region to achieve negative reactivity insertion. In this way the reactor is
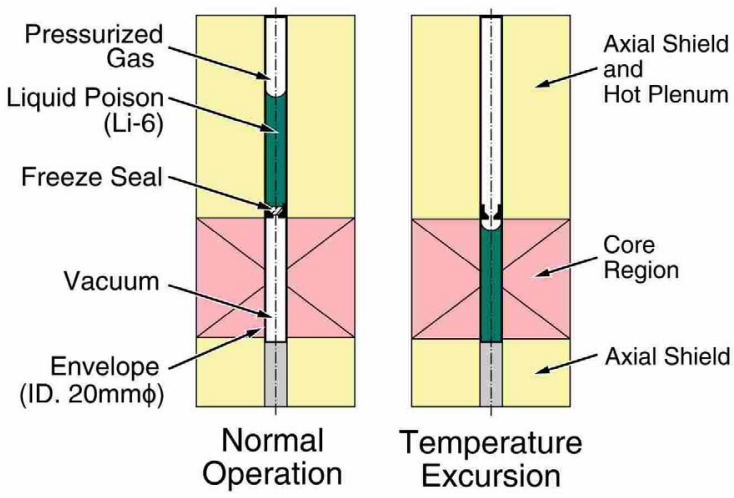

Fig.5 LIM concept automatically brought into a permanently subcritical state and temperatures are kept well below the boiling point of lithium $\left(1330^{\circ} \mathrm{C}\right)$. LIM is also effective independent of the magnitude and direction of the gravity force. According to our experiment ${ }^{10}$, the time required for reactivity insertion of LIM is $0.24 \mathrm{~s}$, which is quite shorter than that of free drop of the conventional scram rods (i.e. as much as $2 \mathrm{~s}$ on the earth ${ }^{1}$ ). Detail of the freeze seal design is discussed in the former paper ${ }^{9-10}$.

\subsection{Lithium Release Module (LRM)}

An automated reactor startup can be achieved by LRM. Figure 6 represents the basic concept. LRM is similar to LIM; however, ${ }^{6} \mathrm{Li}$ is reserved in the active core level prior to the reactor startup. The LRM should be placed in the active core region where the local coolant void worth is positive, as is also the case with LEM and LIM. RAPID-L is equipped with an LRM bundle in which 16 LRMs are installed. The reactivity worth of an LRM bundle is $+3.7 \$$ in the case that $95 \%$ enriched ${ }^{6} \mathrm{Li}$ is enclosed in each 20 -mm-diam envelope. An automated startup can be achieved by gradually increasing the primary 
coolant temperature by the primary pumps circulation. Then the freeze seal of LRMs melt down at melting temperature of the freeze seal, and ${ }^{6} \mathrm{Li}$ is released from lower level (active core level) to upper level to achieve positive reactivity addition. In case the freeze seal support material of

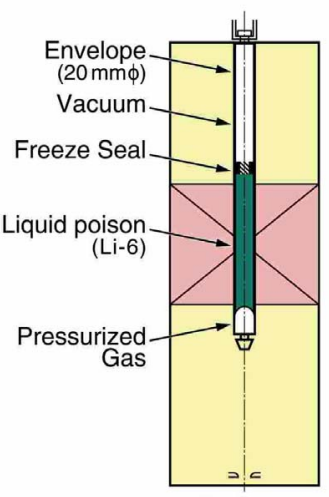

Before Startup

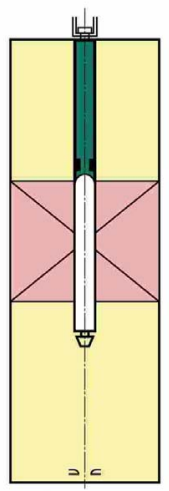

Startup Completed

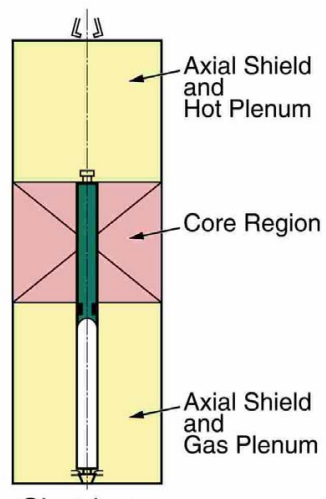

Shutdown
Fig.6 LRM concept

$\mathrm{Ag}-72 \mathrm{Cu}$ is adopted, the injection starts at $800^{\circ} \mathrm{C}$. Because $\mathrm{Ag}-\mathrm{Cu}$ alloy has various range of melting temperature depending on the composition, LRM of desired trigger temperature could be available. Fortunately injected Li stays over the active core region which is colder than the active core region, condensation of Li into the hot side will not occur. Even if condensation occurs, mass transfer through a $0.5 \mathrm{~mm}$ diameter orifice would be negligible.

Detail of the LRM freeze seal as well as the orifice is shown in Fig. 7. To, achieve moderate reactivity insertion rate LRM is equipped with an orifice of $0.5 \mathrm{~mm}$ diameter. In the reactor startup, lithium in the LRM melts at $181^{\circ} \mathrm{C}$ while the freeze seal still remain solid to isolate top and bottom chambers until its melting temperature $\left(800^{\circ} \mathrm{C}\right.$ or $1030^{\circ} \mathrm{C}$, for detail, refer to chapter 4). Performance of the orifice is discussed in chapter 5.

\subsection{Location of the Reactivity Control Systems in the Fuel Cartridge}

As mentioned earlier, the conventional $\mathrm{B}_{4} \mathrm{C}$ poison rods are also equipped in RAPID-L. The role of $\mathrm{B}_{4} \mathrm{C}$ rods is to ensure the criticality safety at launch phase accident, especially on the fire which results in unintended positive reactivity insertion by LRMs because LRM freeze seal melts at $800^{\circ} \mathrm{C}$. Location of these devices in the fuel cartridge is shown in Fig. 8 which illustrates the horizontal cut section of the fuel cartridge at $1 \mathrm{~m}$ below the NsL (Normal System Level). Specifications of these systems are summarized in Table 3.

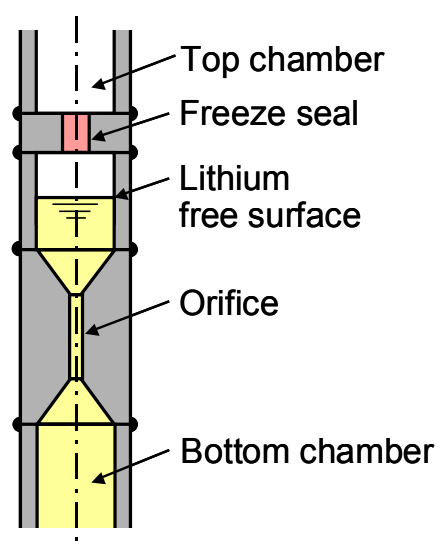

Fig.7 Detail of the freeze seal and orifice

Table 3 Design parameters of the RAPID-L reactivity control systems

\begin{tabular}{|c||c|c|}
\hline Reactivity control system & Envelope inner diameter $(\mathrm{mm})$ & Number \\
\hline \hline B $_{4}$ C poison rod & 20 & 8 \\
\hline LRM & $20[40 \text { or } 60]^{*}$ & $16[\mathrm{TBD}]^{*}$ \\
\hline Slow LEM & 20 & 24 \\
\hline Quick LEM & 20 & 4 \\
\hline LIM & 20 & 16 \\
\hline
\end{tabular}

*) In case envelope inner diameter of the LRM is 40 or $60 \mathrm{~mm}$ as shown in chapter 5.1, number of such LRMs would be less than 16 . 


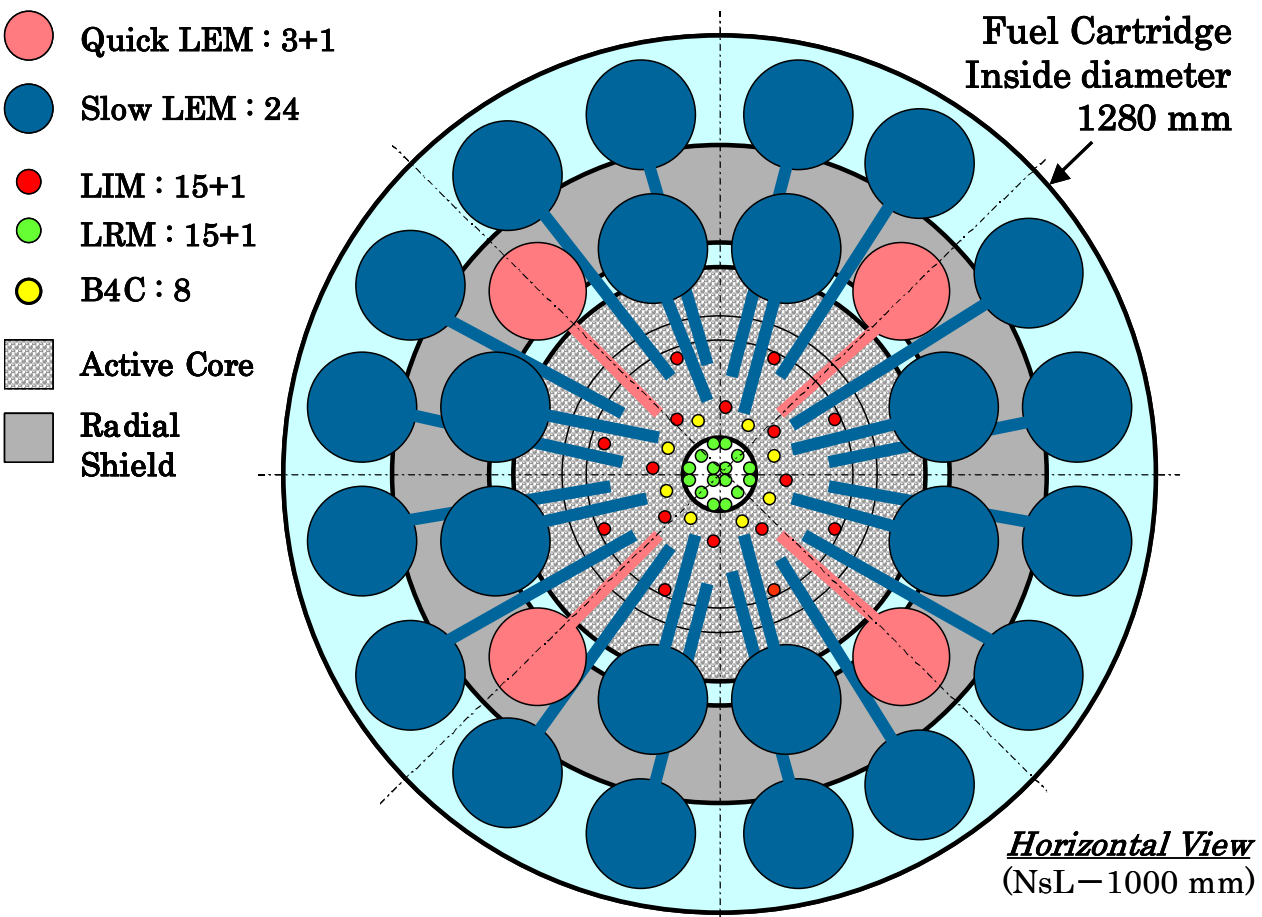

Fig.8 RAPID-L reactivity control systems

\section{Reactor Startup}

\subsection{Startup Sequence}

In the startup sequence adopted here ${ }^{11}$, heat up the reactor from $-100^{\circ} \mathrm{C}$ to $+200^{\circ} \mathrm{C}$ is done by external heat source, while heat up the reactor from $200^{\circ} \mathrm{C}$ to $1100^{\circ} \mathrm{C}$ is achieved by reactor power itself, as shown below.

from $200^{\circ} \mathrm{C}$ to $800^{\circ} \mathrm{C}$ by pulling the $\mathrm{B}_{4} \mathrm{C}$ poison rods

from $800^{\circ} \mathrm{C}$ to $1030^{\circ} \mathrm{C}$ by the first LRMs $(1.35 \$ / 2 \mathrm{hr}=1.13 \phi / \mathrm{min})$

from $1030^{\circ} \mathrm{C}$ to $1100^{\circ} \mathrm{C}$ by the second LRMs $(1 \$ / 7 \mathrm{hr}=0.24 \phi / \mathrm{min})$

To achieve this startup sequence, the melting temperatures of the first and second LRM freeze seals are $800^{\circ} \mathrm{C}$ and $1030^{\circ} \mathrm{C}$, respectively.

\subsection{Plant Dynamics Analysis of the Startup Transient}

Results of the plant dynamics analyses ${ }^{11}$ are shown in Fig. 9. The reactor startup is done as follows.

1) After having been installed the reactor on the lunar base, the primary coolant lithium is circulated at its nominal flow rate, and poison rods are released by drive motor, then criticality is attained at $200^{\circ} \mathrm{C}$.

2) Further release of the poison rods will result in increase of the core exit temperature up to $800^{\circ} \mathrm{C}$. Then the first LRM freeze seal melts, and positive reactivity insertion by the first LRM $(1.35 \$ / 2 \mathrm{hr}=1.13 \notin / \mathrm{min})$ takes place. This reactivity insertion rate is as moderate as that manually inserted by control rods in conventional fast reactors. During this period, greater variation of the reactor power is perceived because of negative reactivity feedback of the fast reactor core. 
3) Positive reactivity addition by the first LRM will result in increase of the core exit temperature up to $1030^{\circ} \mathrm{C}$. Then the second LRM freeze seal melts, and positive reactivity insertion by the second LRM $(1 \$ / 7 \mathrm{hr}=0.24 \phi / \mathrm{min})$ takes place. In the reactivity vs. time relation in Fig. 9, reactivity of the second LRM starts from $0 \notin$ at 5 $\mathrm{hr}$ from the startup, however, the first LRM keeps $530 \phi$ even after the second LRM initiated the injection.

4) LRM release is completed and the nominal core exit temperature of $1100^{\circ} \mathrm{C}$ is attained. In this final sequence, slow LEMs and quick LEMs have important roles. Slow LEM would provide negative reactivity feedback beyond $1085^{\circ} \mathrm{C}$ (refer to Fig. 4) to counterbalance positive reactivity addition by LRMs. Final negative reactivity feedback by slow LEM would be $3 \$$ which compensate the excess reactivity of the beginning-of-life (BOL) core. In the final approach to the nominal power, especially 6-7 $\mathrm{hr}$ from the reactor startup, quick LEMs would be also actuated to provide negative reactivity feedback to restrict reactor overpower. Negative reactivity feedback of slow LEM would gradually decrease as burnup goes on to keep the reactor power as nominal as possible. 

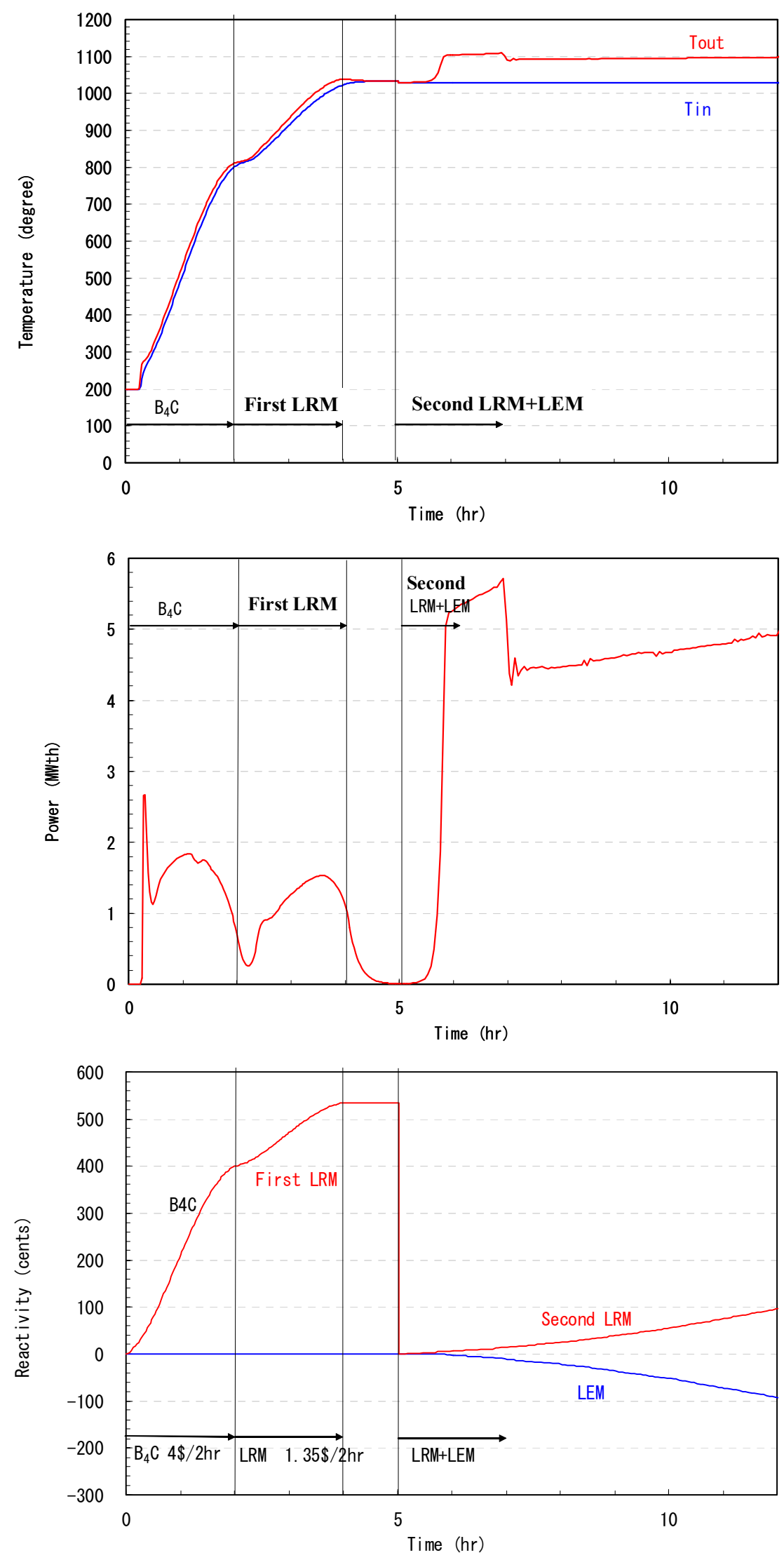

Fig. 9 Plant dynamics analyses of the RAPID-L startup sequence ${ }^{11}$ 


\section{Development of the Lithium Release Module (LRM)}

\subsection{Requirements on the LRM Orifice}

Our primary concern in the LRM design is how to achieve sufficiently small flow rate of ${ }^{6} \mathrm{Li}$ in the orifice because it enables moderate positive reactivity insertion rate. To realize startup sequence presented in the former chapter, requirements for the orifice flow rate of the first and second LRMs are given as follows.

\section{1) First LRM}

Required reactivity insertion rate:

Active core height: $600 \mathrm{~mm}$

LRM envelope inner diameter: $40 \mathrm{~mm}$

Volume of ${ }^{6} \mathrm{Li}$ in the envelope:

Specific weight of Li:

$(\pi / 4) \times 4^{2} \times 60=754 \mathrm{~cm}^{3}=754 \times 10^{-6} \mathrm{~m}^{3}$

$510 \mathrm{~kg} / \mathrm{m}^{3}$ at $200^{\circ} \mathrm{C}$

$450 \mathrm{~kg} / \mathrm{m}^{3}$ at $800^{\circ} \mathrm{C}$

Weight of ${ }^{6} \mathrm{Li}$ in the envelope:

Required mass flow rate:

$385 \mathrm{~g}\left(=754 \mathrm{~cm}^{3} \times 0.51\right)$ at $200^{\circ} \mathrm{C}$

$385 \mathrm{~g} / 2 \mathrm{hr}=\mathbf{3 . 2} \mathrm{g} / \mathrm{min}$

\section{2) Second LRM}

Required reactivity insertion rate:

Active core height:

LRM envelope inner diameter:

Volume of ${ }^{6} \mathrm{Li}$ in the envelope:

Specific weight of Li:

Weight of ${ }^{6} \mathrm{Li}$ in the envelope:

Required mass flow rate:

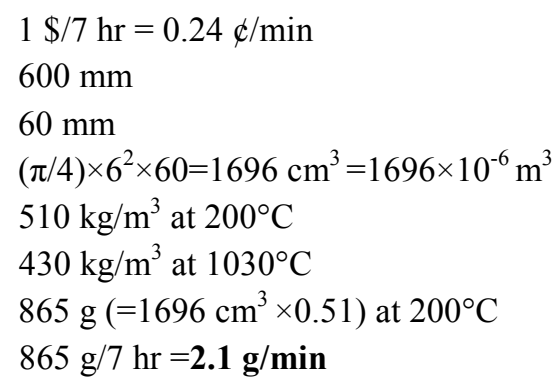

\subsection{Measurement of the Orifice Flow Rate}

To confirm the orifice performance specified above, an orifice of $0.5 \mathrm{~mm}$ diameter and $15 \mathrm{~mm}$ long made of SUS316 was adopted as shown in Fig. 10. In view of the compatibility with lithium over $800^{\circ} \mathrm{C}$, however, orifice made of MoRe or $\mathrm{NbZr}$ alloy is requested. Either boring by spark erosion or mechanical drilling could manufacture such small diameter orifice made of these refractory metals. This manufacturing is a proven technology and it is easy to provide such orifice of sufficient accuracy. Lithium of "battery grade" was used to avoid plugging of the impurities in such a small diameter orifice.

A schematic of the test setup is shown in Fig. 11. To realize situation in the LRM, the orifice specimen is connected to the lithium reservoir to which an $\mathrm{Ar}$ gas circuit is connected to exert difference pressure. Another end of the orifice is connected to the lithium discharge line from which lithium droplet comes out as shown in Fig. 12. The test setup is placed in the glove box and heated over $200^{\circ} \mathrm{C}$ using trace heater. Weight of lithium coming out is measured with respect to time to calculate lithium flow rate in the orifice. The actual operating temperature of LRM is 800 to $1100^{\circ} \mathrm{C}$ as shown in the chapter 4.1 ; however, lower temperature of the test setup is sufficient so long as correction on the lithium property is done.

One of the test results is shown in Figs. 13 and 14. As shown in chapter 5.1, required mass flow rate is $3.2 \mathrm{~g} / \mathrm{min}$ for the first LRM and $2.1 \mathrm{~g} / \mathrm{min}$ for the second LRM. Orifice difference pressures to achieve such flow rate are given in Fig. 14. The orifice difference pressure in Fig. 13 is slightly different between Run 1 and 2. However, both data coincides well on the orifice difference pressure vs. mass flow rate relation as shown in Fig. 14. 
(Orifice Detail)
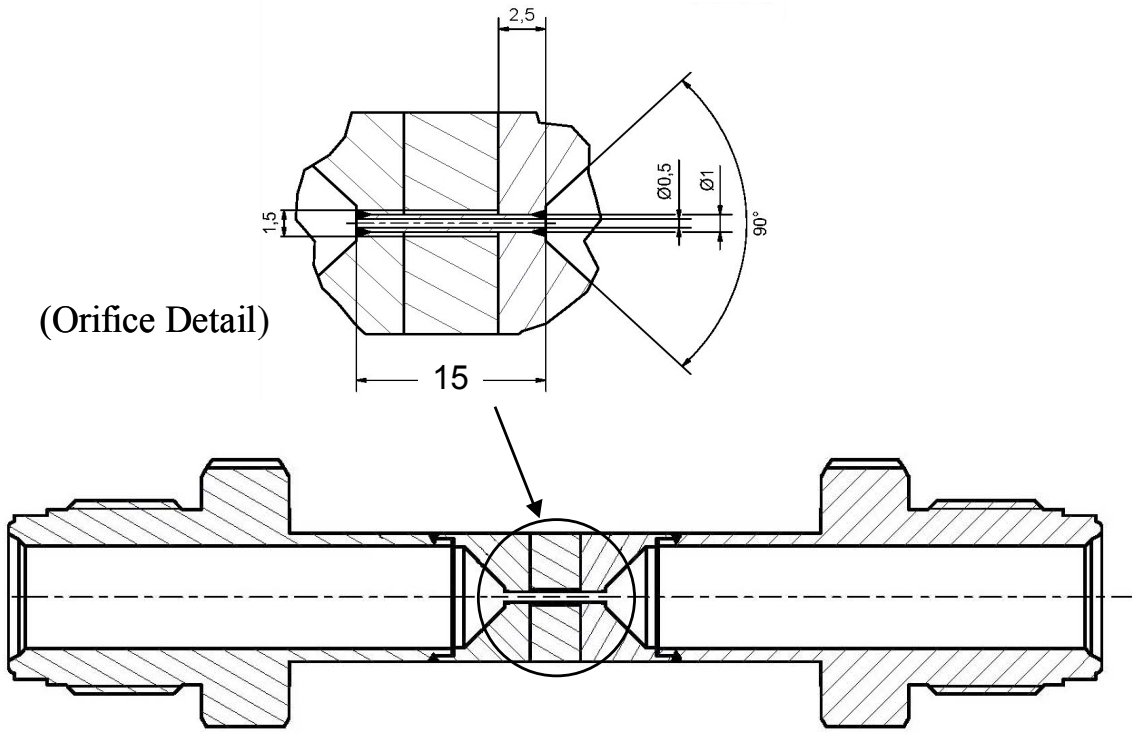

Fig. 10 Orifice specimen

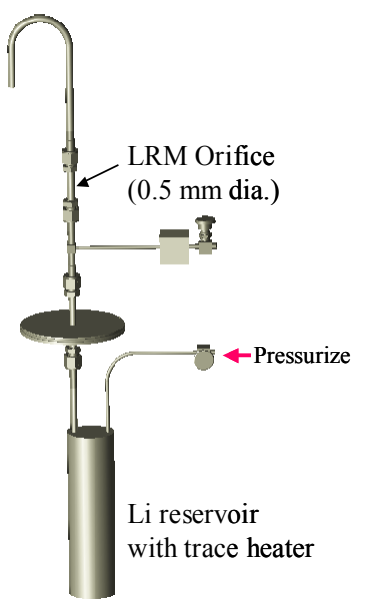

Fig. 11 Schematic of the test setup

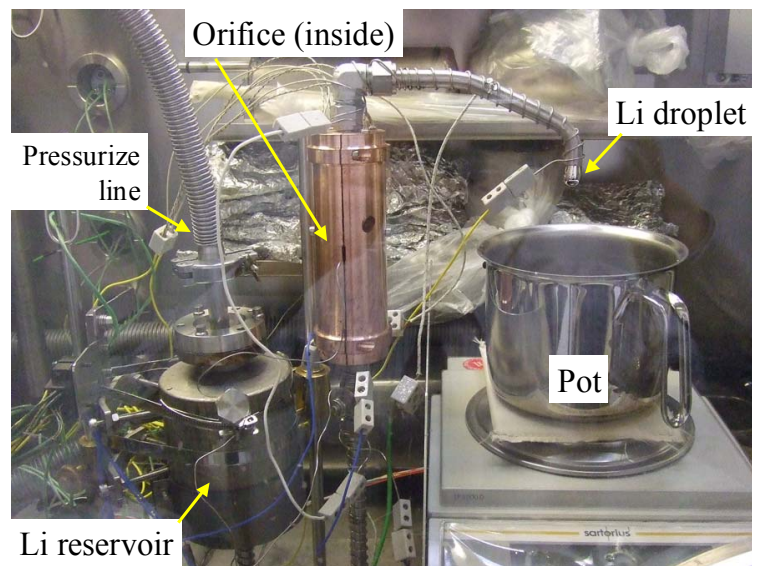

Fig. 12 Test setup in the glove box

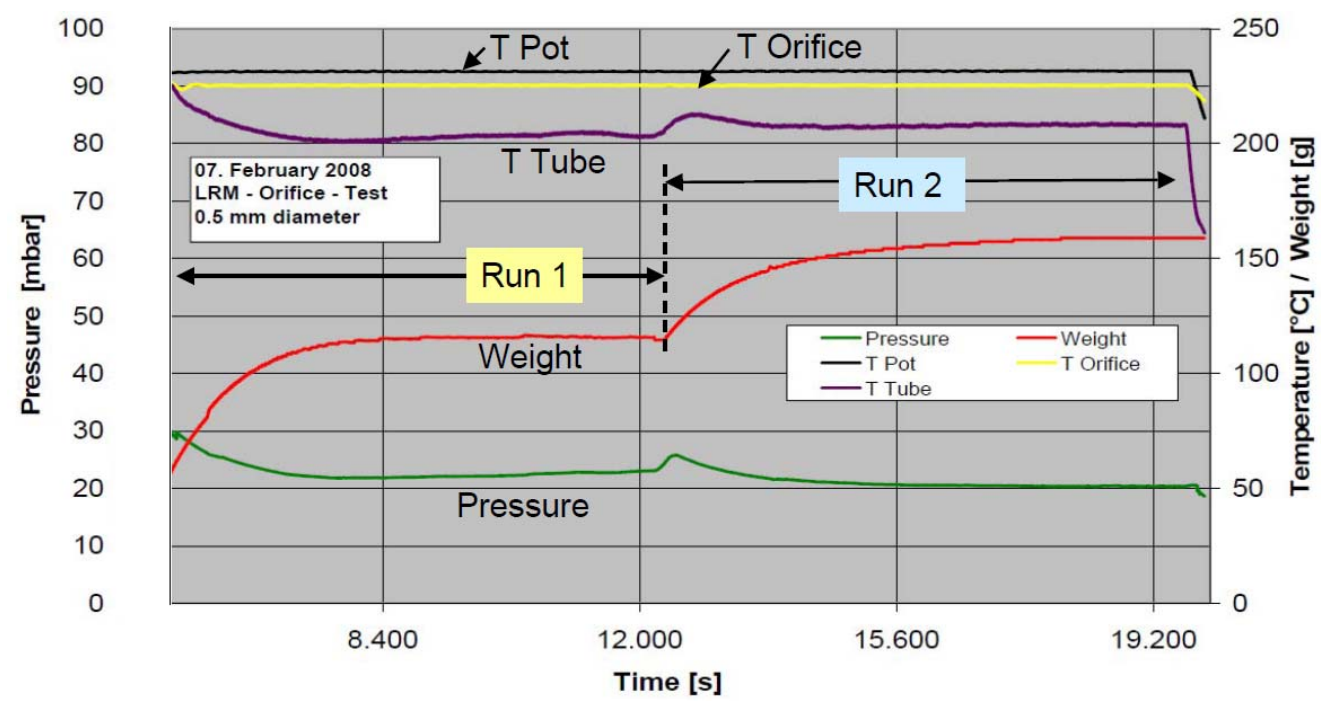

Fig. 13 Orifice test result 


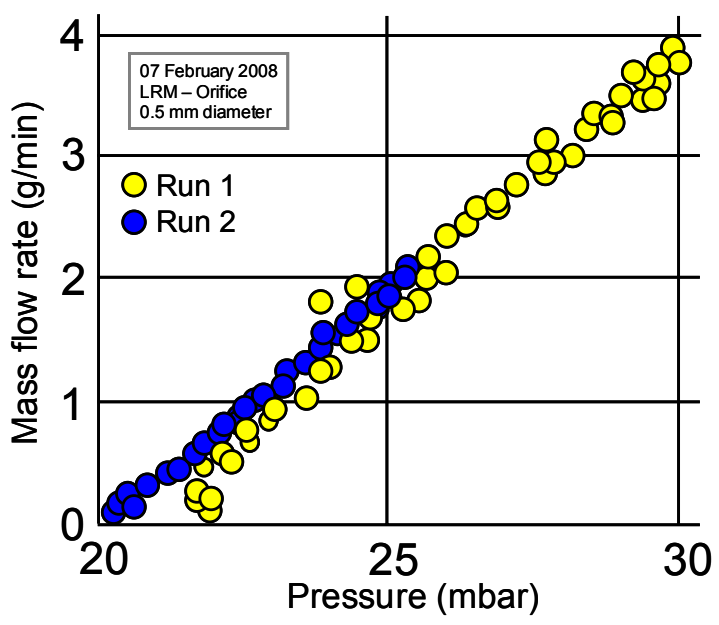

Fig. 14 Orifice difference pressure vs. mass flow rate

The orifice coefficient is the most important parameter in the LRM design because the orifice coefficient together with the difference pressure determines the orifice flow rate, i.e. positive reactivity insertion rate. The orifice is characterized by the following basic equations. As shown in equation (1), the orifice performance does not depend on $\mathrm{g}$ (acceleration of the gravity) but on $\rho(=\gamma / \mathrm{g}$ : viscosity of Li).

$$
\begin{aligned}
& \mathrm{V}=\mathrm{C}\left(2 \mathrm{~g} \Delta \mathrm{P}_{\mathrm{o}} / \gamma\right)^{1 / 2} \\
& \left(\pi \mathrm{d}^{2} / 4\right) \mathrm{Vt} \gamma=\mathrm{W}
\end{aligned}
$$

where

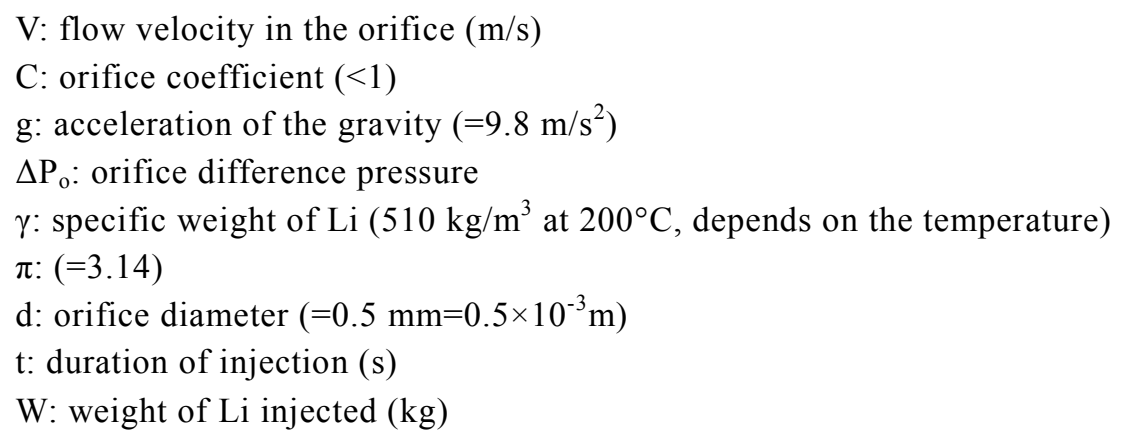

Orifice coefficient $\mathrm{C}$ is given by the equations (1) and (2).

$$
\mathrm{C}=\mathrm{V} /\left(2 \mathrm{~g} \Delta \mathrm{P}_{\mathrm{o}} / \gamma\right)^{1 / 2}=\mathrm{W} /\left[\left(\pi \mathrm{d}^{2} / 4\right) \mathrm{t} \gamma\left(2 \mathrm{~g} \Delta \mathrm{P}_{\mathrm{o}} / \gamma\right)^{1 / 2}\right]
$$

However, pressure loss due to hydrodynamic friction in the orifice: $\Delta \mathrm{P}_{\text {Fric }}$ should be also taken into account. It is estimated by the following equations. Friction coefficient $\lambda$ is available by equation (5) so long as lithium in the orifice is laminar flow (i.e. Reynolds number lass than 2320). Then the orifice coefficient $\mathrm{C}$ is calculated using the effective orifice difference pressure: $\Delta \mathrm{P}_{\mathrm{o}}$ given by the equation (6). The orifice coefficient calculated is listed in Table 4. The orifice coefficient defined in equation (1) was 0.17 and 0.12 for the first and second LRM, respectively. It seems that the orifice coefficient is not always constant, but depends on the flow rate. The hydrodynamic friction is lass than $20 \%$ of the total deference pressure. 


$$
\begin{aligned}
& \Delta \mathrm{P}_{\text {Fric }}=\lambda \times(\mathrm{L} / \mathrm{d}) \times\left(\mathrm{V}^{2} \gamma / 2 \mathrm{~g}\right) \\
& \lambda=64 / \operatorname{Re} \\
& \Delta \mathrm{P}_{\mathrm{o}}=\Delta \mathrm{P}_{\text {Total }}-\Delta \mathrm{P}_{\text {Fric }}
\end{aligned}
$$

where

$$
\begin{aligned}
& \mathrm{V} \text { : flow velocity in the orifice }(\mathrm{m} / \mathrm{s}) \\
& \mathrm{Re}: \text { Reynolds number }(=\mathrm{Vd} / \mathrm{v}) \\
& \mathrm{d} \text { : orifice diameter }\left(=0.5 \mathrm{~mm}=0.5 \times 10^{-3} \mathrm{~m}\right) \\
& \mathrm{v} \text { : dynamic viscosity of } \mathrm{Li}\left(=1.1 \times 10^{-6} \mathrm{~m}^{2} / \mathrm{s} \text { at } 200^{\circ} \mathrm{C}\right) \\
& \lambda \text { : friction coefficient }(=64 / \mathrm{Re} \text { in case } \mathrm{Re}<2320) \\
& \Delta \mathrm{P}_{\text {Total }} \text { : overall orifice difference pressure } \\
& \Delta \mathrm{P}_{\text {Fric }} \text { : pressure loss due to hydrodynamic friction } \\
& \Delta \mathrm{P}_{\mathrm{o}} \text { : effective orifice difference pressure with respect to the orifice } \\
& \quad \text { coefficient }\left(=\Delta \mathrm{P}_{\text {Total }}-\Delta \mathrm{P}_{\text {Fric }}\right) \\
& \mathrm{C} \text { : orifice coefficient } \\
& \mathrm{g}: \text { acceleration of the gravity }\left(=9.8 \mathrm{~m} / \mathrm{s}^{2}\right)
\end{aligned}
$$

Table 4 Orifice coefficient

\begin{tabular}{|c||c|c|c|c|c|c|c|}
\hline & $\mathrm{V}$ & $\mathrm{Re}$ & $\lambda$ & $\Delta \mathrm{P}_{\text {Total }}$ & $\Delta \mathrm{P}_{\text {Fric }}$ & $\Delta \mathrm{P}_{\mathrm{o}}$ & $\mathbf{C}$ \\
$(\mathrm{m} / \mathrm{s})$ & & & $(\mathrm{mbar})$ & $(\mathrm{mbar})$ & \\
\hline \hline First LRM & 0.50 & 230 & 0.28 & 28 & 5.5 & 22.5 & $\mathbf{0 . 1 7}$ \\
\hline Second LRM & 0.35 & 160 & 0.40 & 26 & 3.8 & 22.2 & $\mathbf{0 . 1 2}$ \\
\hline
\end{tabular}

In order to achieve required flow rate, the initial filling pressure of the LRM bottom chamber is calculated based on the Boyle-Charles law. As shown in Table 5, quite lower absolute pressure is required for the initial filling pressure that could be achieved by adjusting the pressure of laser welding chamber in which LRM bottom chamber is sealed.

Table 5 Required initial filling pressure of the LRM bottom chamber

\begin{tabular}{|c||c|c|c|}
\hline & $\begin{array}{c}\text { Required flow rate } \\
\text { (Flow velocity in the orifice: } \mathrm{V} \\
\text { and orifice coefficient: } \mathrm{C})\end{array}$ & $\begin{array}{c}\text { Required } \\
\text { operating } \\
\text { condition }\end{array}$ & $\begin{array}{c}\text { Initial filling } \\
\text { pressure at } 20^{\circ} \mathrm{C}\end{array}$ \\
\hline \hline First LRM & $\begin{array}{c}3.2 \mathrm{~g} / \mathrm{min} \\
(\mathrm{V}=0.50 \mathrm{~m} / \mathrm{s}, \mathrm{C}=0.17)\end{array}$ & $\begin{array}{c}28 \mathrm{mbar} \\
\text { at } 800^{\circ} \mathrm{C}\end{array}$ & $\mathbf{7 . 6} \mathbf{~ m b a r}$ \\
\hline $\begin{array}{c}\text { Second } \\
\text { LRM }\end{array}$ & $\begin{array}{c}2.1 \mathrm{~g} / \mathrm{min} \\
(\mathrm{V}=0.35 \mathrm{~m} / \mathrm{s}, \mathrm{C}=0.12)\end{array}$ & $\begin{array}{c}26 \mathrm{mbar} \\
\text { at } 1030^{\circ} \mathrm{C}\end{array}$ & $\mathbf{5 . 8} \mathbf{~ m b a r}$ \\
\hline
\end{tabular}

\section{Conclusion}

An operator-free fast reactor concept RAPID-L has been demonstrated by adopting innovative reactor control systems LEM, LIM and LRM. In our latest design, $\mathrm{B}_{4} \mathrm{C}$ poison 
rods are also introduced to ensure criticality safety in all accidental situations. Requirements on the lithium release module (LRM) to startup RAPID-L has been discussed, and the LRM orifice performance has been confirmed using $0.5 \mathrm{~mm}$ diameter SUS316 orifice/lithium flow test setup in the glove box.

The following results have been obtained:

1) Sufficiently small flow rate $(3.2$ and $2.1 \mathrm{~g} / \mathrm{min}$ for the first and second LRMs, respectively) of ${ }^{6} \mathrm{Li}$ in the $\mathrm{LRM}$ orifice is required to achieve moderate positive reactivity insertion rate (1.13 and $0.24 \phi / \mathrm{min}$ for the first and second LRMs, respectively).

2) The orifice coefficient of $0.5 \mathrm{~mm}$ diameter SUS316 orifice was 0.17 and 0.12 for the first and second LRM, respectively. It seems that the orifice coefficient is not always constant, but depends on the flow rate.

3) In order to achieve required flow rate of the orifice, the initial filling pressure of the LRM bottom chamber is calculated. Quite lower absolute pressure (7.6 and 5.8 mbar for the first and second LRMs, respectively) is required for the initial filling pressure that could be achieved by adjusting the pressure of laser welding chamber in which LRM bottom chamber is sealed.

4) After reactor coolant is heated up to $800^{\circ} \mathrm{C}$ by means of the $\mathrm{B}_{4} \mathrm{C}$ poison rods, reactor startup can be performed by the first and second LRMs automatically.

Further development on the LRM is focused on the freeze seal to achieve startup temperature of 800 and $1030^{\circ} \mathrm{C}$ for the first and second LRMs, respectively.

The definite advantage of RAPID-L is that it can exclude human error. The design concept outlined above offers a substantial inherent safety, and will meet the future space power requirements.

\section{Acknowledgment}

This work is funded by CRIEPI internal funding support. The author wish to acknowledge the contribution of Dr. Patrick Schäfer and Mr. H. G. Mayer of KE-Technologie GmbH of the Stuttgart University for their assistance in executing LRM experiments.

\section{References}

1. S. Kotake, S. Itooka, H. Matumiya and K. Koyama, "Study on a Self Actuated Shutdown System (1)," Trans. of 1993 Fall Meeting of the Atomic Energy Society of Japan (in Japanese), Kobe, Japan, October 9-11, p. 210, The Atomic Energy Society of Japan (1993).

2. M. Edelmann, W. Baumann, A. Bertram, M. Küchle, G. Kussmaul and W. Väth, "Enhanced Thermal Expansion Control Rod Drive Lines for Improving Passive Safety of Fast Reactors," Int. Conf. on Design and Safety of Advanced Nuclear Power Plants, Tokyo, October 25-29, P. 29. 4-1, The Atomic Energy Society of Japan (1992).

3. S. Kasai, H. Igakura, K. Matsumoto, I. Ikarimoto, K. Nakai and S. Kotake, "A Study of Enhanced Thermal Elongation Mechanism (ETEM) of Control Rod Drive Line (1), -Trial Fabrication and Static Test of the ETEM-," Trans. of 1993 Fall Meeting of the Atomic Energy Society of Japan (in Japanese), Kobe, Japan, October 9-11, p. 212, The Atomic Energy Society of Japan (1993).

4. R. T. Lanced, E. R. Specht, M. Cooper, R. Adkins, H. S. Bailey, A. L. Grantz and A. Millunzi, "Inherently Safe Reactor Design," Proc. of the Int. Conf. on Optimization of 
Sodium-Cooled Fast Reactors, London, November 28-December 1, p. 101, The British Nuclear Energy Society (1977).

5. G. C. Slovic, G. J. Van Tuyle and S. Sands, "Assessment of PRISM Responses to Loss of Flow Events," Int. Conf. on Design and Safety of Advanced Nuclear Power Plants, Tokyo, October 25-29, p. 26. 5-1, The Atomic Energy Society of Japan (1992).

6. J. A. BERNARD, K. S. KWOK, T. WASHIO, J. WYANT and F. THOME, "Experimental Demonstration of the MIT-SNL Period-Generated Minimum Time Control Laws for Rapid Increases of Reactor Power from Subcritical Conditions," Space Nuclear Power Systems 1989, p.381-392, Orbit Book Company (1992).

7. M. Kambe, H. Tsunoda, K. Mishima and T. Iwamura, "RAPID-L Operator Free Fast Reactor Concept Without Any Control Rods," Nuclear Technology, 143, July 2003, p. 1-11 (2003).

8. M. Kambe and M. Uotani., "Fast Reactor Concept RAPID for Improvement of Reactor Performance and Proliferation Resistance", Nuclear Engineering and Design, No. 170/1-3, pp.09-19, July 1997.

9. M. Kambe and M. Uotani, "Design and Development of Fast Breeder Reactor Passive Reactivity Control Systems: LEM and LIM," Nuclear Technology, 122, May 1998, p. 179 (1998).

10. M. Kambe, "Experimental and Analytical Investigation of the Fast Reactor Passive Shutdown System: LIM,” Journal of Nuclear Science and Technology, Vol.43, No.6, pp. 635-647, June 2006.

11. M. Kambe, O. Sato and H. Tsunoda, "Startup Sequence of RAPID-L Fast Reactor for Lunar Base Power System," Paper No. 2012, Proceeding of Space Nuclear Conference 2007 (SNC 2007), Embedded Topical Meeting to American Nuclear Society (ANS) 2007 Annual Meeting, Boston, USA, 26 June 2007.

\section{Nomenclature}

RAPID: Refueling by All Pins Integrated Design

RAPID-L: Refueling by All Pins Integrated Design-Lunar base

LEM: Lithium Expansion Module

LIM: Lithium Injection Module

LRM: Lithium Release Module

UTOP: Unprotected Transient Overpower

ISSS: inherent secondary shutdown system

GEM: gas expansion module

ULOF: unprotected loss of flow

ISI: In-Service Inspection

TE: Thermoelectric

NSL: Normal System Level

Re: Reynolds number 